\title{
Memory enhancement for emotional words: Are emotional words more vividly remembered than neutral words?
}

\author{
ELIZABETH A. KENSINGER and SUZANNE CORKIN \\ Massachusetts Institute of Technology, Cambridge, Massachusetts
}

\begin{abstract}
Individuals are more likely to remember negative information than neutral information. In the experiments reported here, we examined whether individuals were also more likely to remember details of the presentation of negative words, as compared with neutral words. In Experiment 1, the rememberknow procedure was used to examine the effect of emotion on the vividness of an individual's memory, showing that remember responses were more frequently assigned to negative words than neutral words. In Experiment 2, a source memory paradigm was used, and again, evidence that individuals' memories were more detailed for negative than for neutral words was found. In Experiments 3-6, we examined the relative contribution of valence and arousal, finding that both dimensions increased the vividness of remembered information (i.e., items with valence only and those that elicited arousal were better remembered than neutral information) but that the effect was greater for words that evoked arousal than for those with valence only. The results support a qualitative, as well as a quantitative, memory benefit for emotional, as compared with neutral, words.
\end{abstract}

Observations in everyday life provide abundantevidence that facts and events associated with strong emotions are better remembered than those lacking emotional richness. The extreme of this effect has been demonstrated in investigations of flashbulb memories, where individuals retain a vivid, almost photographic memory of an emotional event (Brown \& Kulik, 1977; Heuer \& Reisberg, 1990; Neisser \& Harsch, 1992; Rubin \& Kozin, 1984). Although flashbulb memories are formed only on rare occasions, experiences in daily life are often infused with emotional relevance. These emotional autobiographical memories are more likely to be recalled than autobiographical events that lack emotional significance. In addition, individuals often feel as though they remember these events in greater detail, and with an enhanced vividness, than events void of emotional import (Conway, 1990; Pillemer, Rhinehart, \& White, 1986).

Many laboratory studies have confirmed that individuals are more likely to remember emotional than neutral information. Thus, if participants are shown a series of emo-

Parts of this article were included in a doctoral dissertation by E.A.K. This research was supported by National Science Foundation Doctoral Dissertation Research Grant BCS0212999, by National Institute of Health Grant AG021525, and by a Howard Hughes Medical Institute Predoctoral Fellowship (to E.A.K.). We thank Helen Barbas, Earl Miller, Gail O'Kane, and Anthony Wagner for helpful discussions. We are grateful to Robert Greene, Vincent Prohaska, and two anonymous reviewers for comments on an earlier version of this manuscript. Correspondence concerning this article should be addressed to E. A. Kensinger, Department of Brain and Cognitive Sciences, Massachusetts Institute of Technology, NE20-392, Cambridge, MA 02139 (e-mail: ekensing@alum.mit.edu). tional and neutral stimuli, they will later recall or recognize a greater proportion of the emotional stimuli than of the neutral stimuli. This emotional memory enhancement effect has been replicated in studies in which pictures, words, sentences, and narrated slide shows have been used (see $\mathrm{Bu}$ chanan \& Adolphs, 2002, and Hamann, 2001, for reviews).

These studies, focusing on the quantitative memory benefit for emotional versus neutral information, however, have neglected to address a critical feature of flashbulb memories and memories for other real-life emotional events: Not only are people more likely to remember this emotional information than they are to remember neutral information, but also they feel that their memories for these emotional events are particularly vivid and contain more contextual detail than is typically the case for memories of neutral events. For example, the hallmark of a flashbulb memory is not the ability to remember simply that the event occurred but, rather, the capacity to retain contextual information, such as where a person was or what they were wearing upon first learning of the event (Neisser \& Harsch, 1992; Rubin \& Kozin, 1984).

\section{Recollection and Familiarity as Processes Contributing to Recognition}

Before returning to this observation, it is first necessary to briefly discuss the literature suggesting that recognition responses may not rely on monolithic processes. Rather, recognition of some items may be based on a detailed vivid feeling of reexperience (recollection), whereas other items may be recognized on the basis of a sense that the item has been previously encountered (a sense of familiarity; Jacoby, 1991; Mandler, 1980; Yonelinas, 2002). 
Recollection is typically equated with the types of processes that are believed to allow correct recall: item-specific information that includes details surrounding the item's presentation. Familiarity, in contrast, lacks this kind of detail and, instead, is a feeling of recent encounter with an item. Recollection is thought to be a slower attention-demanding process, whereas assessments of familiarity are faster and more automatic (see Yonelinas, 2002, for a review).

Recollection and familiarity can be distinguished when participants are asked to determine whether they remember or know stimuli from a list (Gardiner \& Java, 1993; Tulving, 1985). A remember response signifies that the individual has a specific memory of the item's presentation, including such information as where it occurred in the list or an association made with the item. In contrast, a know response indicates that an individual has a sense that the item was previously encountered but lacks any detailed information about its presentation. Recent neuroimaging evidence suggests that the processes contributing to remember and know responses may rely on dissociable prefrontal and medial temporal lobe networks, with processes leading to remember responses recruiting left-lateralized prefrontal regions and the hippocampus and processes leading to know responses being supported by right-lateralized prefrontal regions and the parahippocampal gyrus (e.g., Davachi, Mitchell, \& Wagner, 2003; Davachi \& Wagner, 2002; Henson, Rugg, Shallice, Josephs, \& Dolan, 1999; Henson, Shallice, \& Dolan, 1999; Kensinger, Clarke, \& Corkin, 2003; Mark \& Rugg, 1998).

Rather than assume that remember and know map directly onto the constructs of recollection and familiarity, as was initially proposed (e.g., Gardiner \& Java, 1993), recent theorists (e.g., Jacoby, Yonelinas, \& Jennings, 1997; Yonelinas, Kroll, Dobbins, Lazzara, \& Knight, 1998) have suggested that recollection and familiarity are independent or orthogonal processes, in contrast to remember and know responses, which are mutually exclusive. In an experimental setting, remember and know are mutually exclusive, because an individual is instructed to give a know response only when he or she does not have the detailed information that would allow a remember response. In reality, however, recognition may often be based on some combination of recollection and familiarity processes; thus, the two processes may not be mutually exclusive. Furthermore, the extent to which recognition for an item is driven by recollection may be independent of the extent to which it is driven by familiarity (e.g., an individual could have a lot of recollection but little familiarity, a lot of recollection and familiarity, or any possible combination). Thus, the two processes may be independent. Because we wished to be agnostic about issues related to exclusivity (as is assumed in remember or know scoring) versus independence (as may characterize the relation between recollection and familiarity), the present research uses remember and know responses, as well as estimates of recollection and familiarity, to address how attention modulation affects the richness of memories for negative, as compared with neutral, items.

\section{Recollection Benefit for Negative Stimuli}

To return to the emotional memory literature, there is reason to believe that individuals may show an enhanced tendency to recollect emotional, as compared with neutral, information. In addition to the studies of real-life events mentioned earlier, there have also been a couple of laboratory studies suggesting that the ability to recollect (Ochsner, 2000) or to remember (Doerksen \& Shimamura, 2001) contextual details may be enhanced by the presence of emotional significance. Ochsner demonstrated that individuals were more likely to recollect negative than to recollect neutral pictures, whereas their ability to sense that the photograph was familiar was less affected by the emotional content of the pictures. He hypothesized that this recollective benefit for negative stimuli results from increased distinctiveness at encoding for these items (i.e., the encoding of item-specific features that have minimal or no overlap with those of other presented items). Doerksen and Shimamura showed that source memory (thought to rely on recollective processes) is better for emotional words than for neutral words. They suggested that this improved source memory may be due to enhanced autobiographical elaboration for the negative than for the neutral words. A study of false memories (Pesta, Murphy, \& Sanders, 2001) has also supported the conclusion that emotional (taboo) information has greater distinctiveness: Individuals were less prone to falsely recognize emotional lures than nonemotional lures, likely because of the increased distinctiveness associated with the emotional items.

\section{Contributions of Valence and Arousal}

In a widely accepted psychological model of emotion, valence (how positive or negative a stimulus is) and arousal (how calming or exciting a stimulus is) are postulated to be orthogonal dimensions in whose space all emotions lie (e.g., Lang, Greenwald, Bradley, \& Hamm, 1993; Russell, 1980). Currently, the relative contributions of the two dimensions (arousal and valence) to the ability to vividly remember emotional information remain underspecified.

Ochsner (2000) has hypothesized that the dimension of arousal may be particularly important. He proposed that some of the distinctiveness provided by emotion stems from the physiological responses resulting from the stimuli. Clearly, emotional arousal is a critical mediator of the memory enhancement effect for many types of information: Pharmacological (e.g., Cahill, Prins, Weber, \& McGaugh, 1994) and stimulus (e.g., Bradley, Greenwald, Petry, \& Lang, 1992; Cahill \& McGaugh, 1995) manipulations that increase arousal levels also enhance subsequent memory performance. The importance of arousal, however, does not negate a contribution by valence. Individuals may be more likely to elaborate on items with valence (activating either semantic or autobiographical information), which could also lead to an enhancement in the ability to vividly recollect these stimuli (because these items would then have been encoded in a more distinct fashion than neutral stimuli). The valence dimension could also affect familiarity-based recognition responses 
if items with valence are processed more fluently or efficiently than neutral items.

The experiments in the present study first confirmed the presence of the recollective (Experiment 1) and source memory (Experiment 2) enhancements for words that were both negatively valenced and arousing. The relative contributions of valence and arousal to the effect were then investigated (Experiments 3-6).

\section{EXPERIMENT 1 Vividness of Memories for Negative and Neutral Words}

The investigation of words creates an interesting followup to the results of Ochsner (2000), because words have fewer attributes associated with them and, thus, are often encoded less distinctly than pictures (Dewhurst \& Conway, 1994; Rajaram, 1993). Words also are easier than pictures to match on a range of dimensions (e.g., frequency or familiarity) that affect memory performance; pictures are more difficult to match for degree of unusualness, visual complexity, and other features that could contribute to distinctive encoding. The goal of Experiment 1 was to assess whether the recollection benefit reported for negative pictures (Ochsner, 2000) would also be present for negative words.

\section{Method}

Participants. Participants consisted of 18 male $^{1}$ MIT undergraduate or graduate students (18-30 years of age, $M=21.5$; 13-18 years of education, $M=15.1)$. The participants gave informed consent and received $\$ 10 / \mathrm{h}$ for their participation. All the participants were right-handed native English speakers. No participant was taking centrally acting medications, had a history of mental illness or depression, or was currently depressed.

Design and Materials. We selected as stimuli 280 words from the Affective Norms for English Words (ANEW; Bradley \& Lang, 1999). One half of the words were neutral, and one half were negative. Negative words were selected to be low in valence and high in arousal. These words have been classified reliably in terms of valence and arousal, and Bradley and Lang have shown that these ratings correspond to physiological changes.

Neutral and negative words were matched pairwise for word frequency (neutral words, $M=30.9, S D=23.4$; negative words, $M=$ 28.9, $S D=26.8$ ), word familiarity (neutral words, $M=496, S D=$ 49.7; negative words, $M=502, S D=46.9$ ), word length (neutral words, $M=5.7, S D=1.3$; negative words, $M=5.9, S D=1.5$ ), and imageability (neutral words, $M=461, S D=137$; negative words, $M=443, S D=129$; Coltheart, 1981; Kučera \& Francis, 1967). They were also matched for the number of abstract versus concrete words. The 280 words were divided into two sets of 140 (70 neutral and 70 negative) words. The sets that served as the study list versus the nonstudied foils on the recognition test were counterbalanced across participants. Words were presented in Geneva, 48-point black font on a Macintosh laptop computer for $2 \mathrm{sec}$ each in a pseudorandom order. Each participant viewed one study list.

Procedure. All the participants completed one testing session lasting approximately $45 \mathrm{~min}$. At the beginning of the study session, the participants were told that they were going to see a series of words and that they should rate each word as abstract or concrete by making a buttonpress with their right middle or right ring fingers, respectively. They were informed that after completion of the study list, they would be given a recognition test.
A self-paced recognition test occurred after a 15-min delay (the delay was filled with a distractor task in which nonverbal stimuli were used). The participants were asked to select whether they vividly remembered the word from the list, knew the word was familiar and believed it had been previously presented, or thought that the word was new (not previously presented).

After completion of the study-test cycle, the participants rated all words (including foils on the recognition test) on a scale of 1-9 for valence $(1=$ highly negative, $9=$ highly positive $)$ and on a scale of 1-9 for arousal $(1=$ highly calming, $9=$ highly arousing; Table 1$)$. These ratings were used to classify the items as negative or neutral for each participant. Separate analyses were conducted using median split of valence ratings to divide words into neutral and negative or using cutoff points (valence of 1-3 for negative, valence of 4-6 for neutral). These methods revealed a very similar grouping of words as negative or neutral, and all the presented data used the cutoff system. There was little interparticipant variability in whether a word was rated as negative or neutral. The selection of the words was such that the negative words were both arousing and low in valence (i.e., negative).

Data analysis. Data were analyzed in two ways. First, we calculated the corrected recognition scores (\% remember hits - \% remember false alarms or \% know hits - \% know false alarms). False alarm rates were computed separately for negative and neutral words; however, because these false alarm rates did not differ $(p>.4)$, we collapsed across foil type when computing the corrected recognition scores.

Second, we computed recollection and familiarity scores, as suggested by Yonelinas et al. (1998). These scores take into account the fact that the probability of making a know response to a presented word was constrained by the number of remember responses made to presented words, because the participants were instructed to respond know to items that were familiar and not recollected.

Recollection was computed by subtracting the proportion of remember false alarms $\left(R_{\text {new }}\right)$ from remember hits $\left(R_{\text {old }}\right)$ and then dividing by the proportion of times a participant could have responded remember correctly ( $1-R_{\text {new }}$, which took into account a person's tendency to give a remember response). Familiarity $\left(F d^{\prime}\right)$ was calculated in two steps. First, the probabilities of correctly responding know to an old item $\left(F_{\text {old }}\right)$ and of incorrectly responding know to a new item $\left(F_{\text {new }}\right)$ were computed. These values $\left(F_{\text {old }}\right.$ and $\left.F_{\text {new }}\right)$ were calculated on the basis of the assumption that the probability of making a know response was constrained by the number of remember responses made. Thus, because a know response could be given only when an item was familiar but could not be recollected, $F_{\text {old }}=$ $K_{\text {old }} /\left(1-R_{\text {old }}\right)$ and $F_{\text {new }}=K_{\text {new }}\left(1-R_{\text {new }}\right)$. These two values $\left(F_{\text {old }}\right.$ and $\left.F_{\text {new }}\right)$ can then be used to calculate the contribution of familiarity $\left(F d^{\prime}\right)$ by using $d^{\prime}$ tables. $F d^{\prime}$ represents the distance between the two response distributions ( $F_{\text {old }}$ and $F_{\text {new }}$ ), with greater values of $F d^{\prime}$ indicating greater assessments of familiarity. Since $F d^{\prime}$ is measur-

Table 1

Valence and Arousal Ratings of Stimuli Used in Experiments 1 and 2

\begin{tabular}{llllll}
\hline & \multicolumn{3}{c}{ Mean Rating (Maximum =9) } \\
\cline { 2 - 3 } \cline { 5 - 6 } & \multicolumn{2}{c}{ Set A } & & \multicolumn{2}{c}{ Set B } \\
\cline { 2 - 3 } Item Type & $M$ & $S D$ & & $M$ & $S D$ \\
\hline Negative & & & & \\
$\quad$ Valence & 1.78 & 0.63 & 1.91 & 0.61 \\
$\quad$ Arousal & 6.95 & 0.53 & 7.16 & 0.72 \\
Neutral & & & & \\
$\quad$ Valence & 5.83 & 0.47 & 5.65 & 0.43 \\
Arousal & 3.12 & 0.93 & 3.35 & 0.87 \\
\hline
\end{tabular}

Notes-Valence, 1 = highly negative, $9=$ highly positive arousal, $1=$ highly calming, $9=$ highly arousing. 
ing the standard deviation between the two distributions, in theory there is no upper bound on $F d^{\prime}$ values, although in practice, the values are unlikely to exceed single digits.

Analyses consisted of repeated measures analyses of variance (ANOVAs) with item type (negative or neutral) and memory response (remember or know) as within-subjects factors and subsequent $t$ tests. All reported $p$ values are two-tailed.

\section{Results}

Corrected recognition scores. Repeated measures ANOVAs indicated a significant effect of item type (Table 2). The $t$ tests confirmed that the participants' memory was better for negative than for neutral words $[t(17)=$ $4.14, p<.01]$. This enhancement was present in 16 of the 18 participants.

Remember and know responses. Repeated measures ANOVAs conducted on the corrected recognition scores (\% hits - \% false alarms) indicated a marginally significant effect of item type, with individuals recognizing more negative words than neutral words $[F(1,17)=3.09$, $p<.10$ ], a significant effect of memory strength, with individuals giving more remember than know responses $[F(1,17)=34.62, p<.001]$, and a significant item type $\times$ memory strength interaction $[F(1,17)=40.60$, $p<.0001]$.

The $t$ tests indicated that the interaction stemmed from the participants' giving a significantly greater proportion of remember responses to negative versus neutral words $[t(17)=7.32, p<.001]$ but a greater proportion of know responses to neutral than to negative words $[t(17)=4.05$, $p<.01]$. The effects were remarkably consistent across participants: All 18 participants responded remember to a greater proportion of negative than of neutral items.

Recollection and familiarity. Recollection was higher for negative than for neutral stimuli $[t(1,17)=7.29, p<$ $.001]$, and familiarity was marginally higher for negative than for neutral words $[t(1,17)=1.90, p<.10]$. Again, the recollectionenhancement was present in all 18 participants.

\section{Discussion}

Experiment 1 indicated that recognition memory was better for negative than for neutral words. This finding is consistent with prior studies in which memory enhancement for emotional, as compared with neutral, stimuli was found (see Hamann, 2001, for a review), including on tests of recognition(Cahill \& McGaugh, 1995; Ochsner, 2000). This general enhancement effect was relatively consistent, occurring in 16 of 18 participants.
Although this finding is interesting on its own, prior studies have shown such enhancement effects and have shown them in the majority of their participants (see Hamann, 2001, for a review). The novel question addressed by Experiment 1 was whether the enhancement effect would stem from increases in recollection (or remember responses) or familiarity (or know responses). When the participants' remember and know responses were analyzed, the enhancement effect appeared to be dominated by the increase in remember responses: The participants gave a significantly greater proportion of remember responses to negative than to neutral words. This result suggests that vivid detailed memories were formed more frequently for negative items than for neutral items. Importantly, this enhancement effect was reliable across participants: All 18 individuals gave a greater proportion of remember responses to negative than to neutral words. The results from the analyses computing recollection reached a similar conclusion: All 18 participants were more likely to use recollection when recalling negative, as compared with neutral, words. These results confirm that the remember or recollection responses are greater to negative items, suggesting that individuals are better able to conjure a detailed memory for a negative than for a neutral event.

This conclusion does not rule out the possibility that individuals may also have a greater sense of familiarity for negative than for neutral items. A number of studies have shown that fluency (i.e., the ease with which an item is processed) is greater for emotional items than for neutral ones (Bargh, Chaiken, Govender, \& Pratto, 1992; Kitayama, 1990; Williams, Mathews, \& MacLeod, 1996). Since familiarity is often equated with this type of fluent processing, it could follow that processes contributing to familiarity may indeed be greater for negative than for neutral items. Consistent with this conclusion, familiarity responses were greater for negative than for neutral items. It is important to point out that the results of the familiarity analyses diverged from those for the know responses: Familiarity was marginally greater for negative items, whereas know responses were given more frequently to neutral items. This discrepancy is likely due to the fact that the remember and know procedure requires participants to make a know response only when the item is recognized but not remembered (i.e., remember and know are mutually exclusive). Familiarity responses, which take into account the fact that recollection and familiarity can drive a correct recognition response jointly, were found to be mar-

Table 2

Experiment 1: Memory Performance as a Function of Item Type

\begin{tabular}{|c|c|c|c|c|c|c|c|c|c|c|c|c|}
\hline \multirow[b]{3}{*}{ Item Type } & \multicolumn{4}{|c|}{ Hit Rate } & \multicolumn{4}{|c|}{ False Alarm Rate } & \multirow{2}{*}{\multicolumn{2}{|c|}{ Recollection }} & \multirow{2}{*}{\multicolumn{2}{|c|}{ Familiarity }} \\
\hline & \multicolumn{2}{|c|}{ Remember } & \multicolumn{2}{|c|}{ Know } & \multicolumn{2}{|c|}{ Remember } & \multicolumn{2}{|c|}{ Know } & & & & \\
\hline & $M$ & $S D$ & $M$ & $S D$ & $M$ & $S D$ & $M$ & $S D$ & $M$ & $S D$ & $M$ & $S D$ \\
\hline Negative & .52 & .22 & .34 & .23 & .03 & .03 & .16 & .21 & .50 & .25 & 1.6 & $\overline{0.80}$ \\
\hline Neutral & .37 & .20 & .38 & .23 & .04 & .05 & .14 & .19 & .28 & .23 & 1.2 & 0.72 \\
\hline
\end{tabular}


ginally larger for negative than for neutral items, suggesting that negative items are both more richly remembered and more frequently sensed to be familiar. The finding of increased familiarity toward negative items is consistent with some prior memory studies (e.g., Ochsner, 2000) and indicates that individuals recognize negative words better, due to increases in recollection and familiarity.

In summary, Experiment 1 showed that memory is enhanced for negative, as compared with neutral, words. This effect appeared to result from increases in both recollection and familiarity, although the increases in recollection were more consistent across participants (occurring in all the individuals tested), whereas the increases in familiarity were less consistent across participants (occurring in 13 of the participants). The results further indicated that even for verbal stimuli, which lack the inherent richness of pictures, and even when emotional and neutral words are matched for characteristics that affect distinctiveness (e.g., frequency, familiarity, and imageability), memory is still better for negative than for neutral stimuli.

\section{EXPERIMENT 2 \\ Source Memory for Negative and Neutral Words}

Recollection and familiarity refer to the subjective richness of a memory. As studies with flashbulb memories have shown (Neisser \& Harsch, 1992; Rubin \& Kozin, 1984; Schmolck, Buffalo, \& Squire, 2000), this subjective vividness is not always correlated with the accuracy of the memory. Individuals often claim to have a very vivid memory of an emotional event and to have high confidence in the accuracy of the memory's details. Nevertheless, these memories are susceptible to the same types of distortions as are memories for neutral events (e.g., Schmolck et al., 2000). We, therefore, wanted to examine whether individuals objectively were remembering more details about the negative than for the neutral words or whether it was only the subjective quality of the memory that differed for the two word types. To address this question, in Experiment 2, we used a source memory task to test objectively the contextual details associated with memory for negative versus neutral verbal stimuli.

\section{Method}

Participants. For Experiment 2, we enrolled 18 male MIT undergraduate or graduate students (18-30 years of age, $M=22.7$; education $=14-19$ years, $M=15.7)$. The participants met the same criteria as those outlined for Experiment 1.

Design and Materials. The stimuli were the same as those in Experiment 1, and the design was identical, except that half of the words were presented in blue font and half in red font (to provide source information).

Procedure. The study procedure was identical to that in Experiment 1 , with the exception that the participants were told that the words would appear in red or blue font and that the subsequent recognition task would require them to indicate the color of the font for each of the words. The recognition procedure was identical to that in Experiment 1, except that the participants were asked to select red, blue, or new.
Data analysis. Corrected recognition scores (\% hits - \% false alarms) were computed to determine item memory. Hits were all words correctly recognized as old (collapsing across red and blue decisions). False alarms were lures incorrectly called old (collapsing across red and blue). Source memory was calculated as the proportion of presented items not called new (i.e., classified as either red or blue) for which the correct color information was selected. Repeated measures ANOVAs with item type (negative or neutral) and memory type (item or source) as within-subjects factors were computed, as were subsequent $t$ tests. All reported $p$ values are twotailed.

\section{Results}

The results showed no bias toward one color or the other in the participants' false alarms ( $48 \%$ red $)$. We, therefore, did not correct for false alarms when calculating source recognition, but item recognition was corrected for false alarm rate. The false alarm rate was calculated separately for the negative and the neutral items; however, because the false alarm rates did not differ $(p>.6)$, we collapsed across foil type when computing the corrected recognition scores.

Repeated measures ANOVAs indicated a significant main effect of item type $[F(1,17)=23.97, p<.0001]$ and memory strength $[F(1,17)=70.88, p<.0001]$ and no interaction between item type and memory strength $[F(1,17)=$ $2.54, p>.1]$. Subsequent $t$ tests indicated that the participants had better item memory $[t(17)=4.44, p<.0001]$ and better source memory $[t(17)=3.60, p<.01]$ for negative than for neutral stimuli (Table 3). As in Experiment 1, the effect was consistent across participants, with 17 of the 18 participants having higher source memory scores for the negative than for the neutral items and 15 of 18 having higher item memory scores for the negative than for the neutral items.

\section{Discussion}

The goal of Experiment 2 was to assess whether results from a task using an objective measure of the richness of a memory (i.e., naming the color in which the word was written) would converge on the findings of Experiment 1, which found that participants have more detailed memories for negative than for neutral items. The results from the source memory test support this conclusion: Individuals more accurately reported the color of font in which a negative word was presented than the color of font in which a neutral word was presented. This result is consistent with Doerksen and Shimamura (2001), who found source

Table 3

Experiment 2: Proportion of Words Correctly Identified as Old (\% Hits - \% False Alarms) and Proportion of Old Items With Correct Source Recognition as a Function of Item Type

\begin{tabular}{ccccc}
\hline & \multicolumn{3}{c}{ Memory } \\
\cline { 2 - 5 } Item Type & \multicolumn{2}{c}{ Item } & & \multicolumn{2}{c}{ Source } \\
\cline { 2 - 5 } \cline { 3 - 5 } & $M$ & $S D$ & & $S D$ \\
\hline Negative & .70 & .10 & .45 & .16 \\
Neutral & .63 & .12 & .32 & .16 \\
\hline
\end{tabular}


memory enhancement for negative, as compared with neutral, stimuli, using a similar task design. As in Experiment 1, the enhancement effect was consistent across participants, occurring in 17 of 18 young adults. Also consistent with Experiment 1, item memory, as well as source memory, was superior for the negative items, although this effect was less consistent across participants.

These results are important because they indicate that emotional content does not enhance only the subjective richness of a memory. Rather, the emotional content of the words increased the likelihood that individuals would remember a specific detail (the color of ink in which the word was presented). Thus, emotional content does appear to enhance the likelihood that a contextual detail will be incorporated into a memory.

Together, the results of Experiments 1 and 2 confirm that the vividness or richness of emotional memories known to occur in everyday life (e.g., Conway, 1990; Pillemer et al., 1986; Rubin \& Kozin, 1984) can be replicated in the laboratory, using controlled stimuli. The next experiments addressed the relative contributions of arousal and valence to the effect.

\section{EXPERIMENT 3 Memory Enhancement for Words: Effects of Valence and Arousal}

The negative words used in Experiments 1 and 2 differed from the neutral words on two dimensions: arousal and valence. These factors may contribute differentially to the emotional memory enhancement effect. Although enhancement effects may result from either valence or arousal, the memory effects based on valence versus arousal may not be equivalent.

To tease apart the memory enhancement effects due to arousal versus those due to arousal and valence, participants encoded two kinds of words: The first was low in valence (i.e., negative) but not arousing (e.g., sorrow). The second was arousing ${ }^{2}$ (i.e., taboo words, such as those for sexual body parts or swear words) but not as negative as the valence-only words (taboo words were selected so that no taboo word was rated as low in valence as any of the negative words). In addition, for the taboo words, arousal and valence were not directly correlated (i.e., words with higher absolute valence ratings were not more arousing than those rated as having moderate valence). In Experiment 3 , we asked whether the enhancement effect would exist for words that differed only in valence and whether the enhancement effect for those items would be as great as that for items that also differed in arousal.

\section{Method}

Participants. The participants consisted of 20 male undergraduate or graduate students at MIT or Harvard (19-33 years of age, $M=$ 21.5; education range $=14-20$ years, $M=15.9$ ). The participants gave informed consent and received $\$ 7$ for their participation. All the participants were right-handed native English speakers. No participant was taking centrally acting medications, had a history of mental illness or depression, or was currently depressed.
Design and Materials. Words included 60 taboo words, 60 negative words, and 60 neutral words. Taboo words were selected to be high in arousal, but not as low in valence as the negative words. Negative words were selected to be low in valence and not arousing (Table 4 reports ratings from all the participants from Experiments 3-6). Neutral words were matched to the taboo and negative words in word length (neutral words, $M=5.8, S D=1.5$; negative words, $M=5.6, S D=$ 1.4 ; taboo words, $M=5.7, S D=1.3$ ) and in the number of abstract and concrete words. We also attempted to match the taboo words to the neutral and negative words in word frequency, using estimates from an Internet search engine (see Blair, Urland, \& Ma, 2002).

Procedure. The participants were shown 90 words (30 taboo, 30 negative, and 30 neutral), 1 at a time, each for $2 \mathrm{sec}$. The words were presented on a Macintosh computer screen (Geneva, 48-point font). The participants rated each word as abstract or concrete. Following a 15-min delay, the participants took a 180 -item recognition test in which they indicated whether they vividly remembered the word from the word list, knew the word was familiar and believed it was previously presented, or believed the word to be new. The words presented at study versus as foils on the recognition test were counterbalanced across participants.

Data analysis. Repeated measures ANOVAs were conducted, with item type (taboo, negative, or neutral) and memory strength (remember/know or recollection/familiarity) as within-subjects factors. Subsequent $t$ tests examined the effects of item type and memory strength.

\section{Results}

Corrected recognition. Overall corrected recognition scores (\% hits - \% false alarms) were first calculated first (Table 5). ${ }^{3}$ Overall, corrected recognition was better for the taboo words than for the negative words $[t(19)=3.52$, $p<.01]$ and for the negative than for the neutral words $[t(19)=2.08, p<.05]$.

Remember and know. The corrected remember and know recognition rates were then calculated as follows (Table 5): \% remember hits $-\%$ remember false alarms (or \% know hits - \% know false alarms). Because the false alarm rate did not differ for taboo, negative, and neutral words (all $p \mathrm{~s}>.5$ ), the same false alarm rates were subtracted for all item types. Repeated measures ANOVAs conducted on these corrected remember and know values indicated significant effects of item type $[F(2,38)=12.06, p<.0001]$ and memory strength $[r e-$

Table 4

Valence and Arousal Ratings of Stimuli Used in Experiments 3-6

\begin{tabular}{ccc}
\hline & \multicolumn{2}{c}{ Mean Rating (Maximum $=9$ ) } \\
\cline { 2 - 3 } Item Type & $M$ & $S D$ \\
\hline Taboo & 3.58 & 0.93 \\
Valence & 8.02 & 0.57 \\
Arousal & & \\
Negative & 1.78 & 0.68 \\
Valence & 3.35 & 0.79 \\
Arousal & & \\
Neutral* & 5.22 & 0.45 \\
Valence & 4.51 & 0.86 \\
Arousal &
\end{tabular}

Note-Valence, 1 = highly negative, $9=$ highly positive ; Arousal, $1=$ highly calming, $9=$ highly arousing. *Ratings collapse across neutral words from Experiments 3-4 and 5-6 (semantic associates); there were no significant differences in the ratings of these two groups of neutral stimuli. 
Table 5

Experiment 3:

Memory Performance as a Function of Item Type

\begin{tabular}{|c|c|c|c|c|c|c|c|c|c|c|c|c|}
\hline \multirow[b]{3}{*}{ Item Type } & \multicolumn{4}{|c|}{ Hit Rate } & \multicolumn{4}{|c|}{ False Alarm Rate } & \multirow{2}{*}{\multicolumn{2}{|c|}{ Recollection }} & \multirow{2}{*}{\multicolumn{2}{|c|}{ Familiarity }} \\
\hline & \multicolumn{2}{|c|}{ Remember } & \multicolumn{2}{|c|}{ Know } & \multicolumn{2}{|c|}{ Remember } & \multicolumn{2}{|c|}{ Know } & & & & \\
\hline & $M$ & $S D$ & $M$ & $S D$ & $M$ & $S D$ & $M$ & $S D$ & $M$ & $S D$ & $M$ & $S D$ \\
\hline Taboo & .80 & .16 & .12 & .11 & .11 & .09 & .10 & .13 & .74 & .16 & 2.1 & 0.9 \\
\hline Negative & .63 & .19 & .16 & .19 & .13 & .14 & .09 & .11 & .57 & .21 & 1.4 & 1.4 \\
\hline Neutral & .50 & .22 & .17 & .14 & .09 & .10 & .08 & .15 & .43 & .23 & 1.1 & 0.9 \\
\hline
\end{tabular}

member, know; $F(1,19)=102.52, p<.0001]$ and a significant interaction between item type and memory strength $[F(2,38)=8.85, p<.001]$. Subsequent $t$ tests confirmed that remember responses were greater for the taboo words than for the negative words $[t(19)=3.82$, $p<.001]$ and were marginally greater for the negative than for the neutral words $[t(19)=1.88, p<.08]$. Know responses were similar between all item types $(p>.3)$.

Recollection and familiarity. Recollection was greater for the taboo words than for the negative words $[t(19)=$ $3.90, p<.001]$ and was marginally greater for the negative than for the neutral words $[t(19)=1.92, p<.07]$. Familiarity was marginally greater for the taboo words than for the negative words $[t(19)=1.82, p<.09]$ and was significantly greater for the taboo words than for the neutral words $[t(19)=4.08, p<.01]$ but did not differ between the negative and the neutral words $(p>.3)$.

\section{Discussion}

In Experiment 3, we examined the enhancement effect for words that differed from the neutral words only in valence versus the effect for words that differed from the neutral words primarily in arousal. The critical findings were that there was memory enhancement for items that differed only in valence but that the enhancement was greatest for items eliciting arousal. As in the prior experiments, enhancement existed at the level of overall recognition scores, as well as with remember responses and recollection. Familiarity was greatest for the taboo words but was similar between the negative and the neutral words. This finding is consistent with those from the literature on fluency enhancement for emotional stimuli; traditionally, the stimuli used have been arousing (Bargh et al., 1992; Christianson, Loftus, Hoffman, \& Loftus, 1991; Williams et al., 1996). Thus, valence and arousal appear to boost recollection, whereas arousal (but not valence) may also serve to boost familiarity.

\section{EXPERIMENT 4 \\ Effects of Valence and Arousal on Memory for Source}

Experiment 3 indicated a difference in the subjective vividness of memories for arousing words versus that for words with valence only. In Experiment 4, we addressed the question of whether this finding is limited to the realm of subjective ratings or would extend to a source memory paradigm that allowed for an objective measurement of the contextual details associated with a memory.

\section{Method}

Participants. The participants included 18 males (18-29 years of age, $M=21.7$; years of education $=12-18$ years, $M=13.5$ ) who met the criteria outlined in Experiment 1.

Materials and Procedure. The materials were the same as those in Experiment 3, and the testing procedures were identical to those in Experiment 2. Data were analyzed in the same way as in Experiment 2.

\section{Results}

ANOVAs indicated significant effects of item type $[F(2,34)=16.71, p<.0001]$ and memory strength $[F(1,17)=27.51, p<.0001]$ and a marginal interaction between item type and memory strength $[F(2,34)=2.50$, $p<.10]$. Subsequent $t$ tests indicated that item memory was marginally better for the negative words than for the neutral words $[t(17)=1.99, p<.07]$ and was similar for the taboo and the negative words. Source memory was greater for the negative words than for the neutral words $[t(17)=2.22, p<.05]$ and was greater for the taboo words than for the negative words $[t(17)=2.49, p<.05$; Table 6]. ANOVAs indicated that false alarm rates did not differ for the three item types.

\section{Discussion}

The critical findings of Experiment 4 were that the participants showed more accurate source memory for the arousing words and for words with valence than they did for the neutral words. The magnitude of the enhancement effect was greater for the taboo words than for the negative words, as in the prior experiment. Thus, not only do individuals subjectively feel that they have more vivid memories for arousing words or words with valence only, but also they perform better on an objective measure of a

Table 6

Experiment 4: Item and Source Memory Performance as a Function of Item Type

\begin{tabular}{lcccc}
\hline & \multicolumn{3}{c}{ Memory } \\
\cline { 2 - 5 } Item Type & $M$ & $S D$ & & \multicolumn{2}{c}{ Source } \\
\cline { 2 - 5 } \cline { 2 - 5 } Item & .15 & .44 & .16 \\
\hline Taboo & .64 & .08 & .31 & .08 \\
Negative & .52 & .11 & .25 & .09 \\
Neutral & .40 & & & \\
\hline
\end{tabular}


memory's vividness. The results of Experiments 3 and 4, therefore, indicate that negative valence alone (i.e., without arousal) is sufficient to increase the vividness of a memory; however, the presence of arousal further increases the likelihood that details will be remembered from an item's presentation.

\section{EXPERIMENT 5 \\ Memory Enhancement: Role of Category Relatedness}

Taboo and negative words can be thought of as categorically related (i.e., taboo is a category, as is negative things). Neutral words, in contrast, have typically been taken from a range of categories, raising the possibility that the memory benefit for the emotional words is due not to their arousal or valence per se but, rather, to their categorical relatedness. In Experiment 5, we addressed this possibility by using neutral words that were all semantic associates.

\section{Method}

Participants. The participants consisted of 18 males who were MIT or Harvard undergraduate or graduate students, 19-32 years of age $(M=27.2)$, with $14-18$ years of education $(M=16.1)$. They met the criteria outlined in Experiment 1.

Design and Materials. The materials and design were identical to those in Experiment 3, except that all the neutral words were associates of the words think or mind. This selection was made because the association was not immediately obvious (i.e., taking all animals would be very easy for participants to notice and could cause easier discrimination of seen and unseen words than would be the case for negative or taboo words). Associates of the words think and mind also have a breakdown between concrete and abstract words similar to that for negative and taboo words. ${ }^{4}$

\section{Results}

Correct recognition. Repeated measures ANOVAs conducted on the correct recognition rates indicated a significant effect of item type $[F(2,34)=11.28, p<.0001]$. Subsequent $t$ tests indicated that memory was better for the taboo words than for the negative words $[t(17)=3.87$, $p<.001]$ or the neutral words $[t(17)=3.43, p<.01]$ but that memory was similar for the neutral and the negative words $(p>.5$; Table 7$)$.

Remember and know. Repeated measures ANOVAs indicated a significant effect of item type $[F(2,34)=$ $11.28, p<.0001$ ], a marginal effect of memory strength $[F(1,17)=4.14, p<.06]$, and an interaction between item type and memory strength $[F(2,34)=8.89, p<$ .001].

Subsequent $t$ tests indicated that remember responses were higher for taboo words than for negative words $[t(17)=2.57, p<.05]$ and were higher for negative than for neutral words $[t(17)=3.04, p<.01]$. Know responses were similar for taboo and negative words $(p>9)$ but were higher for neutral than for negative words $[t(17)=$ 2.87, $p<.05$ ] and for neutral than for taboo words $[t(17)=2.19, p<.05$; Table 7].

Recollection and familiarity. Recollection was higher for taboo than for negative words $[t(17)=2.56$, $p<.05]$ and was higher for negative than for neutral words $[t(17)=3.43, p<.01]$. Familiarity was marginally greater for taboo than for negative words $[t(17)=$ $1.80, p<.09$ ] and was similar for negative and neutral words $(p>.2)$.

\section{Discussion}

The critical finding of Experiment 5 was that the memory enhancement for the negative items remained even when the neutral items were semantic associates. This finding suggests that the memory enhancement for the negative items is not attributable only to the semantic relatedness of the negatively valenced or arousing words.

\section{EXPERIMENT 6 \\ Recall of Words With Valence and Arousal}

Although the results of Experiment 5 reduced the concern that individuals might be using semantic integration to boost their memory for the taboo, or valenced, items, another possible confound was that of word frequency. Although the negative and the neutral words were matched for word length and word frequency, the taboo words' frequencies were estimated from an on-line search. There was a reasonable probability that the taboo words occurred on the Internet with more frequency than would be the case in other written texts. It was, therefore, possible that differences in word frequency affected recognition responses. Specifically, since recognition rates have been found to be better for low-frequency words than for highfrequency words (e.g., Kintsch, 1970; Mandler, 1980), it remained possible that the memory benefit for the taboo words, as compared with the negative or the neutral words, resulted from the fact that the taboo words had a lower word frequency.

Table 7

Experiment 5: Memory Performance as a Function of Item Type

\begin{tabular}{|c|c|c|c|c|c|c|c|c|c|c|c|c|}
\hline \multirow[b]{3}{*}{ Item Type } & \multicolumn{4}{|c|}{ Hit Rate } & \multicolumn{4}{|c|}{ False Alarm Rate } & \multirow{2}{*}{\multicolumn{2}{|c|}{$\underline{\text { Recollection }}$}} & \multirow{2}{*}{\multicolumn{2}{|c|}{$\underline{\text { Familiarity }}$}} \\
\hline & \multicolumn{2}{|c|}{ Remember } & \multicolumn{2}{|c|}{ Know } & \multicolumn{2}{|c|}{ Remember } & \multicolumn{2}{|c|}{ Know } & & & & \\
\hline & $M$ & $S D$ & $M$ & $S D$ & $M$ & $S D$ & $M$ & $S D$ & $M$ & $S D$ & $M$ & $S D$ \\
\hline Taboo & .54 & .16 & .35 & .20 & .01 & .05 & .11 & .15 & .53 & .16 & 2.2 & 1.1 \\
\hline Negative & .41 & .20 & .36 & .19 & .03 & .09 & .13 & .13 & .39 & .20 & 1.6 & 0.9 \\
\hline Neutral (semantic associates) & .30 & .17 & .44 & .18 & .02 & .07 & .10 & .13 & .29 & .17 & 1.8 & 0.7 \\
\hline
\end{tabular}


The effects of word frequency are reversed in recall tasks in which items are grouped into lists of similar frequencies (e.g., Gillund \& Shiffrin, 1984; Gregg, 1976): Individuals will typically remember more items from a list of low-frequency words than they will from a list of highfrequency words. Thus, if the memory benefit for the taboo words was due only to differences in word frequency, the reverse effect (i.e., poorer memory for the taboo words) should occur on a recall task.

\section{Method}

Participants. The participants were 16 males (18-28 years of age, $M=20.7 ; 12-16$ years of education, $M=13.2$ ). All met the criteria outlined in Experiment 1.

Materials and Procedure. The materials were 150 words (50 neutral, 50 with valence only, 50 with arousal), taken from those used in Experiment 5. These materials were divided into six lists, each with 25 words of a particular category (e.g., 25 words with arousal). The participants studied one of these lists of 25 words, with each word presented for $2 \mathrm{sec}$. They judged whether each word was abstract or concrete. Three buffer items were inserted at the beginning and end of the list to control for primacy and recency effects. After viewing the list of words, the participants were asked to write down all the words that they remembered from the list. This procedure was then repeated until the participants had studied one list of words from each stimulus category (i.e., neutral, with valence only, and with arousal). The order of the lists and the lists administered were pseudorandomized across participants.

\section{Results}

ANOVAs indicated a significant effect of item type $[F(2,28)=15.16, p<.001]$. Subsequent $t$ tests indicated that the participants recalled more taboo words than negative words $[t(15)=2.88, p<.05]$ or neutral words $[t(15)=5.31, p<.0001]$ and more negative words than neutral words $[t(15)=3.11, p<.01$; Table 8].

\section{Discussion}

Recall rates were higher for items with valence or arousal than for words that were neutral, and the effect was greater for the items with arousal than for those with valence only. Thus, the memory benefit for these emotional words does not appear to have been due to word frequency effects; if this factor had been the major contributor, the effect should have been reversed when a blocked-design recall task was used, as compared with a recognition task. The fact that both recognition and recall rates were higher for words with emotion (valence or arousal) than for neutral words suggests that the memory benefit resulted from factors independent of word frequency. In addition, the fact that the memory benefit existed even when the neu-

Table 8

Experiment 6: Percentage of Words Recalled as a Function of Item Type

\begin{tabular}{lcc}
\hline & \multicolumn{2}{c}{ Recall } \\
\cline { 2 - 3 } Item Type & $M$ & $S D$ \\
\hline Taboo & 61.3 & 18.2 \\
Negative & 45.0 & 14.8 \\
Neutral & 36.5 & 10.6 \\
\hline
\end{tabular}

tral words were all semantic associates suggests that categorical similarity (e.g., semantic elaboration based on category membership) may not be a sufficient explanation for the memory enhancement effect.

\section{GENERAL DISCUSSION}

In the present investigation, we examined whether there was a qualitative memory benefit for emotional, as compared with neutral, words. The results of six experiments confirmed that there is such a benefit: Across all tasks, details associated with the presentation of words (assessed through subjective and objective measures) were more likely to be remembered for emotional than for neutral items. The benefit emerged for words that had valence only, as well as for words with arousal, although the magnitude of the effect was greater for words evoking arousal.

This result is consistent with those in the literature on flashbulb memories (e.g., Brown \& Kulik, 1977) indicating that people feel that they remember the circumstances surrounding emotional events with particular vividness. The data also align with clinical reports from combat veterans or victims of violent crimes, who experience vivid "flashbacks" or a sense of reexperiencing the prior event (Witvliet, 1997). Importantly, in the present study, the verbal stimuli could be controlled for variables known to affect memory (e.g., exposure duration), which cannot be controlled for when assessing memory for autobiographical events. Thus, even with controlled stimuli presented in a laboratory setting, emotional content increases the likelihood that details of an item's presentation will be remembered.

This finding is important because it suggests that emotion serves to increase not only the likelihood that an emotional experience will be remembered, but also the details that one will remember about that event. Thus, the conscious experience of reexperiencing an event is more likely to occur if the event had emotional importance. At least for negative events, this recollective enhancement occurred for items that had only valence, as well as for items that elicited arousal.

What processes may have contributed to the recollective enhancement effect? A critical contributor to this enhancement likely stems from the increased distinctiveness of emotional information. Although distinctiveness is a somewhat nebulous concept (see Hunt \& McDaniel, 1993), we use it to mean the uniqueness of an item (e.g., Rajaram, 1993): Distinctive items share few features with other information in memory or with items in a particular study epoch. Just as pictures are more distinctive than words, because there are more unique attributes associated with pictures than with words (Dewhurst \& Conway, 1994; Rajaram, 1993), so are emotional stimuli postulated to be more distinctive than neutral stimuli. Emotion provides a number of additional dimensions (e.g., personal relevance or physiological response) not present with neutral stimuli (Christianson et al., 1991; Ochsner, 2000). Thus, just as pictures are better remembered than words, due at least 
in part to their enhanced distinctiveness, it could be that emotional stimuli are better remembered than neutral stimuli because of their increased distinctiveness.

Critically, the results of the present investigation indicate that although the dimension of physiological arousal does enhance the ability to vividly remember a prior event, it is not a necessary feature. Even words with valence only were more likely to be vividly remembered than neutral words. Thus, if increased distinctiveness does explain the memory enhancement, there must be additional dimensions that contribute distinctiveness to emotional items, aside from features related to an individuals' physiological response to that stimulus. There may be additional elaborative processes (e.g., evaluative processes or autobiographical elaboration) that increase the distinctiveness of the encoded valence-only words, as compared with the neutral words. These elaborative processes could then underlie the enhanced ability to vividly remember, or reexperience, the presentation of the valence-only words. These processes may also be critical for the enhanced recollection of arousing words, with these words benefiting additionally from the physiological responses elicited by the stimuli.

Another possibility is that emotion serves as a unifying theme to memories, allowing items to be more easily clustered as individuals encode the information. Since emotional information is categorically related, it is likely that this factor is often a contributor to the enhancement effect. The results of the present study, however, suggest that the categorical link of emotional information may not be the only factor. Even when neutral words were chosen to be categorically associated, memory for the emotional words remained better, and estimates of recollection remained greater, for the words with valence only or with arousal, as compared with the neutral words. It is still possible that this selection of neutral words did not fully control for the relatedness of the emotional categories of words, and thus, further studies will be needed to examine the contribution of semantic clustering to the enhancement effect. It is also possible that categorical relatedness is affected by such factors as encoding instructions or delay intervals and that, under different conditions than those in the present study, semantic relatedness would play a more dominant role. Nevertheless, the results suggest that, at least in some instances, the memory enhancement for emotional information (either with valence only or with arousal) is supported by factors other than categorical relatedness.

Another contributor toward the recollective enhancement effect may be related to attentional biases for negative, as compared with neutral, stimuli. Negative items often seem to capture attention and to be given prioritized processing (Christianson \& Fallman, 1990; Pratto \& John, 1991; Williams et al., 1996). For example, participants made more shadowing errors in a dichotic listening task when highly arousing words were heard in their unattended ear than when less arousing words were presented (Nielsen \& Sarason, 1981). This biasing of attention could increase the likelihood that an emotional word is elaborated upon or could increase the efficiency with which individuals can access information about a negative, as compared with a neutral, item. These factors could increase the likelihood that an emotional item will later be vividly remembered.

As this discussion highlights, a number of processes could potentially contribute to the enhanced ability to vividly remember emotional stimuli. Future experiments will be required to tease apart the relative contributions of these types of processes (e.g., semantic elaboration, evaluative processing, or attentional modulation) to the ability to vividly remember negatively emotional information.

Although the recollective enhancement effect was the dominant effect, present across all the experiments and replicable in nearly all the participants, there was also a tendency toward an enhancement in familiarity, particularly for the arousing words. This enhancement may reflect the fact that, in addition to increasing the use of elaborative encoding strategies or enhancing an item's distinctiveness, negative words may also be processed at a perceptual or conceptual level with greater fluency or efficiency than is the case for neutral words (Bargh et al., 1992; Christianson et al., 1991; Loftus, Loftus, \& Messo, 1987; Öhman, Flykt, \& Lundqvist, 1999; Williams et al., 1996). For example, perceptual benefits for emotional information are suggested by studies indicating that individuals are better able to perceive aversive stimuli in a complicated visual display (Öhman, Flykt, \& Esteves, 2001), during an attentional blink (Anderson \& Phelps, 2001) or while directing attention to another spatial location (Vuilleumier, Armony, Driver, \& Dolan, 2001; Vuilleumier \& Schwartz, 2001; but see Pessoa, Kastner, \& Ungerleider, 2002).

Since the studies mentioned above used negative stimuli that were also arousing, it remains possible that it is the arousal dimension in particular that is critical for this increased fluency of processing. This pattern would explain the results of the present experiment, in which individuals showed enhanced (or marginally enhanced) familiarity for arousing words, but not for words with valence only. Further investigations will be necessary to examine whether valence alone is sufficient to enhance the fluency or efficiency of processing.

In summary, the results of the present study indicate that individuals remember emotional words with more detail than they remember neutral words. Thus, processes that contribute to recollection or to the formation of source memory appear to be modulated by the presence of emotion. The effect is strongest when words have arousal but is also present when words have valence only. There may also be an enhancement in familiarity for items with arousal, although effects of arousal on familiarity do not appear to be as great as the effects on recollection. These findings extend the results of prior studies by indicating that there is not only a quantitative memory benefit for emotional information, but also a qualitative one. 


\section{REFERENCES}

Anderson, A. K., \& Phelps, E. A. (2001). Lesions of the human amygdala impair enhanced perception of emotionally salient events. $\mathrm{Na}$ ture, 17, 305-309.

Bargh, J. A., Chaiken, S., Govender, R., \& Pratto, F. (1992). The generality of the attitude activation effect. Journal of Personality \& Social Psychology, 62, 893-912.

Blair, I. V., UrLand, G. R., \& MA, J. E. (2002). Using Internet search engines to estimate word frequency. Behavior Research Methods, Instruments, \& Computers, 34, 286-290.

Bradley, M. M., Greenwald, M. K., Petry, M. C., \& Lang, P. J. (1992). Remembering pictures: Pleasure and arousal in memory. Journal of Experimental Psychology: Learning, Memory, \& Cognition, 18, 379-390.

Bradley, M. M., \& LANG, P. J. (1999). Affective norms for English words [CD-ROM]. Gainesville: University of Florida, NIMH Center for the Study of Emotion and Attention.

Brown, R, \& Kulik, J. (1977). Flashbulb memories. Cognition, 5, 7399.

Buchanan, T., \& Adolphs, R. (2002). The role of the human amygdala in emotional modulation of long-term declarative memory. In S. Moore \& M. Oaksford (Eds.), Emotional cognition: From brain to behavior (pp. 9-34). London: Benjamins.

Cahill, L., \& McGaugh, J. L. (1995). A novel demonstration of enhanced memory associated with emotional arousal. Consciousness \& Cognition, 4, 410-421.

Cahill, L., Prins, B., Weber, M., \& McGaugh, J. L. (1994). Betaadrenergic activation and memory for emotional events. Nature, 371, $702-704$.

Christianson, S.-A., \& Fallman, L. (1990). The role of age on reactivity and memory for emotional pictures. Scandinavian Journal of Psychology, 31, 291-301.

Christianson, S,-A., Loftus, E. F., Hoffman, H., \& Loftus, G. R. (1991). Eye fixations and memory for emotional events. Journal of Experimental Psychology: Learning, Memory, \& Cognition, 17, 693 701.

Coltheart, M. (1981). The MRC psycholinguistic database. Quarterly Journal of Experimental Psychology, 33A, 497-505.

Conway, M. A. (1990). Autobiographical memory: An introduction. Philadelphia: Open University Press.

Davachi, L., Mitchell, J. P., \& Wagner, A. D. (2003). Multiple routes to memory: Distinct medial temporal lobe processes build item and source memories. Proceedings of the National Academy of Sciences, 100, 2157-2162.

DAVACHI, L., \& WAgner, A. D. (2002). Hippocampal contributions to episodic encoding: Insights from relational and item-based learning. Journal of Neurophysiology, 88, 982-990.

Dewhurst, S. A., \& Conway, M. A. (1994). Pictures, images, and recollective experience. Journal of Experimental Psychology: Learning, Memory, \& Cognition, 20, 1-11.

Doerksen, S., \& Shimamura, A. (2001). Source memory enhancement for emotional words. Emotion, 1, 5-11.

GARDINER, J. M., \& JAVA, R. I. (1993). Recognizing and remembering. In A. F. Collins, S. E. Gathercole, M. A. Conway, \& P. E. Morris (Eds.), Theories of memory (pp. 163-188). Hove, U.K.: Erlbaum.

GeER, J. H., \& McGlone, M. (1990). Sex differences in memory for erotica. Cognition \& Emotion, 4, 71-78.

Gillund, G. G., \& Shiffrin, K. M. (1984). A retrieval model for both recognition and recall. Psychological Review, 91, 1-67.

GREGG, V. (1976). Word frequency, recognition, and recall. In J. Brown (Ed.), Recall and recognition (pp. 183-216). New York: Wiley.

Hamann, S. (2001). Cognitive and neural mechanisms of emotional memory. Trends in Cognitive Sciences, 5, 394-400.

Henson, R. N., Rugg, M. D., Shallice, T., Josephs, O., \& Dolan, R. J. (1999). Recollection and familiarity in recognition memory: An event-related functional magnetic resonance imaging study. Journal of Neuroscience, 19, 3962-3972.

Henson, R. N., Shallice, T., \& Dolan, R. J. (1999). Right prefrontal cortex and episodic memory retrieval: A functional MRI test of the monitoring hypothesis. Brain, 122, 1367-1381.
Heuer, F., \& Reisberg, D. (1990). Vivid memories of emotional events: The accuracy of remembered minutiae. Memory \& Cognition, 18, 496-506.

Hunt, R. R., \& McDaniel, M. A. (1993). The enigma of organization and distinctiveness. Journal of Memory \& Language, 32, 421-445.

JACOBY, L. L. (1991). A process dissociation framework? Separating automatic from intentional uses of memory. Journal of Memory \& Language, 30, 513-541.

Jacoby, L. L., Yonelinas, A. P., \& Jennings, J. M. (1997). The relation between conscious and unconscious (automatic) influences: A declaration of independence. In J. D. Cohen \& J. W. Schooler (Eds.), Scientific approaches to consciousness: Carnegie Mellon Symposia on Cognition (pp. 13-47). Hillsdale, NJ: Erlbaum.

Kensinger, E. A., Clarke, R. J., \& Corkin, S. (2003). What neural processes support encoding and retrieval? An $\mathrm{f} M R I$ study using a divided attention paradigm. Journal of Neuroscience, 33, 2407-2415.

KINTSCH, W. (1970). Learning, memory, and conceptual processes. New York: Wiley.

KITAYAmA, S. (1990). Interaction between affect and cognition in word perception. Journal of Personality \& Social Psychology, 58, 209-217.

KuČERA, H., \& Francis, W. N. (1967). Computational analysis of present-day American English. Providence, RI: Brown University Press.

Lang, P. J., Greenwald, M. K., Bradley, M. M., \& Hamm, A. O. (1993). Looking at pictures: Affective, facial, visceral, and behavioral reactions. Psychophysiology, 30, 261-273.

Lewis, R. J., Gibbons, F. X., \& Gerrard, M. (1986). Sexual experience and recall of sexual versus nonsexual information. Journal of Personality, 54, 676-693.

Loftus, E. F., Loftus, G., \& Messo, J. (1987). Some facts about "weapon focus." Law \& Human Behavior, 11, 55-62.

MAndler, G. (1980). Recognizing: The judgment of previous occurrence. Psychological Review, 87, 252-271.

MARK, R. E., \& RUGG, M. D. (1998). Age effects on brain activity associated with episodic memory retrieval. An electrophysiological study. Brain, 12, 861-873.

Murnen, S. K., \& Stockton, M. (1997). Gender and self-reported sexual arousal in response to sexual stimuli: A meta-analytic review. Sex Roles, 37, 135-153.

Neisser, U., \& Harsch, N. (1992). Phantom flashbulbs: False recollections of hearing the news about Challenger. In E. Winograd \& U. Neisser (Eds.), Affect and accuracy in recall: Studies of "flashbulb" memories (pp. 9-31). Cambridge: Cambridge University Press.

Nielson, S. L., \& SARASON, I. G. (1981). Emotion, personality, and selective attention. Journal of Personality \& Social Psychology, 41, 945-960.

OCHSNER, K. N. (2000). Are affective events richly "remembered" or simply familiar? The experience and process of recognizing feelings past. Journal of Experimental Psychology: General, 129, 242-261.

Öhman, A., Fly KT, A., \& Esteves, F. (2001). Emotion drives attention: Detecting the snake in the grass. Journal of Experimental Psychology: General, 130, 466-478.

Öhman, A., Flykt, A., \& LUndQvist, D. (1999). Unconscious emotion: Evolutionary perspectives, psychophysiological data, and neuropsychological mechanisms. In R. Lane \& L. Nadel (Eds.), Cognitive neuroscience of emotion (pp. 296-327). Oxford: Oxford University Press.

Pessoa, L., Kast ner, S., \& Ungerleider, L. G. (2002). Attentional control of the processing of neural and emotional stimuli. Brain Research: Cognitive Brain Research, 15, 31-45.

Pesta, B. J., Murphy, M. D., \& Sanders, R. E. (2001). Are emotionally charged lures immune to false memory? Journal of Experimental Psychology: Learning, Memory, \& Cognition, 27, 328-338.

Pillemer, D. B., Rhinehart, E. D., \& White, S. H. (1986). Memories of life transitions: The first year in college. Human Learning, 5, 109-124.

Pratto, F., \& John, O. P. (1991). Automatic vigilance: The attentiongrabbing power of negative social information. Journal of Personality \& Social Psychology, 61, 380-391.

RAJARAM, S. (1993). Remembering and knowing: Two means of access to the personal past. Memory \& Cognition, 21, 89-102.

Rubin, D. C., \& KozIn, M. (1984). Vivid memories. Cognition, 16, 81-95.

Russell, J. A. (1980). A circumplex model of affect. Journal of Personality \& Social Psychology, 39, 1161-1178. 
Schmolck, H., Buffalo, E. A., \& SQuire, L. R. (2000). Memory distortions develop over time: Recollections of the O. J. Simpson trial verdict after 15 and 32 months. Psychological Science, 11, 39-45.

Tulving, E. (1985). Varieties of consciousness and levels of awareness in memory. In A. Baddeley \& L. Weiskrantz (Eds.), Attention: Selection, awareness and control. A tribute to Donald Broadbent (pp. 283299). Oxford: Oxford University Press, Clarendon Press.

Vuilleumier, P., Armony, J. L., Driver, J., \& Dolan, R. J. (2001). Effects of attention and emotion on face processing in the human brain: An event-related f MRI study. Neuron, 30, 829-841.

Vuilleumier, P., \& Schwartz, S. (2001). Beware and be aware: Capture of spatial attention by fear-related stimuli in neglect. NeuroReport, 12, 1119-1122.

Williams, J. M. G., Mathews, A., \& MacLeod, C. (1996). The emotional Stroop task and psychopathology. Psychological Bulletin, 120, 3-24.

Witv Liet, C. V. (1997). Traumatic intrusive imagery as an emotional memory phenomenon: A review of research and explanatory information processing theories. Clinical Psychology Review, 17, 509-536.

Yonelinas, A. P. (2002). The nature of recollection and familiarity: A review of 30 years of research. Journal of Memory \& Language, 46, 441-517.

Yonelinas, A. P., Kroll, N. E., Dobbins, I., Lazzara, M., \& Knight, R. T. (1998). Recollection and familiarity deficits in amnesia: Convergence of "remember"-"know," process dissociation, and receiver operating characteristic data. Neuropsychology, 12, 323-339.

\section{NOTES}

1. Men were tested because they have been shown to have greater emotional arousal to sexual information than do women (e.g., Murnen \& Stockton, 1997), resulting in better memory for this sexual information (e.g., Geer \& McGlone, 1990; Lewis, Gibbons, \& Gerrard, 1986). For Experiments 3-6, this ability to find stimuli high in arousal, but not low in valence, was critical).

2. Physiological measurements taken in our laboratory in a separate group of 20 males, matched in age and education, indicated that the taboo words elicited physiological changes [increased heart rate and blood pressure; $t(1,19)>2.2, p<.05$ ], whereas negative nonarousing words did not.

3. The careful reader may note that performance in Experiment 3 is higher than that in Experiment 1. This variability in performance likely stems from the fact that the participants encoded more words in Experiment 1 ( 140 words) than in Experiment 3 (90 words).

4. Another group of 18 males was run on an alternative version with neutral words being related to the categories of household or financial. The critical findings replicated those discussed in Experiment 5.

(Manuscript received April 22, 2003; revision accepted for publication July 4, 2003). 